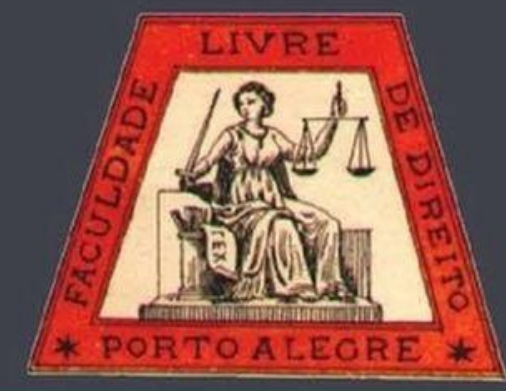

\title{
A reforma do Ensino Médio com base na Lei 13.415/2017 e as implicações no ensino jurídico
}

The implication in juridical teaching of the reform of high school based on Law $n^{\circ}$ 13.415/17

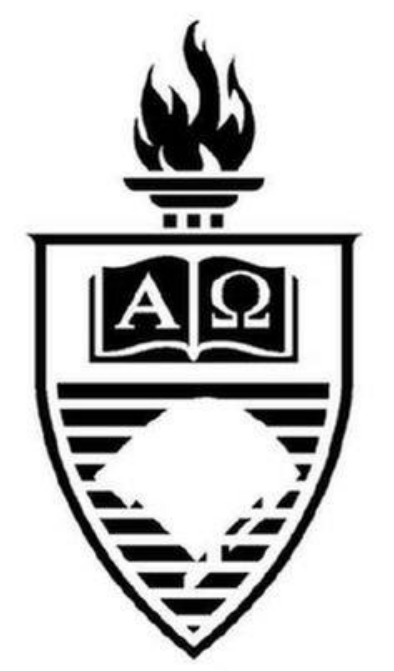

\section{Rosendo Freitas de Amorim Universidade de Fortaleza}

Inês Mota Randal Pompeu

Universidade de Fortaleza

Manuela Brito Câmara

Universidade de Fortaleza

Jefrei Almeida Rocha

Universidade Federal do Ceará

\section{UFRGS}




\title{
A reforma do Ensino Médio com base na Lei 13.415/2017 e as implicações no ensino jurídico
}

\author{
The implication in juridical teaching of the reform of high school based on Law $n^{o}$ \\ $13.415 / 17$
}

Rosendo Freitas de Amorim*

Inês Mota Randal Pompeu**

Manuela Brito Câmara ${ }^{* * *}$

\section{REFERÊNCIA}

Jefrei Almeida Rocha ${ }^{* * * *}$

AMORIM, Rosendo Freitas De; POMPEU, Inês Mota Randal; CÂMARA, Manuela Brito; ROCHA, Jefrei Almeida. A reforma do Ensino Médio com base na Lei 13.415/2017 e as implicações no ensino jurídico. Revista da Faculdade de Direito da UFRGS, Porto Alegre, n. 39, p. 172-188, dez. 2018

\begin{abstract}
RESUMO
A presente pesquisa analisa a reforma no Ensino Médio do Brasil proposta pela Lei $N^{\circ} 13.415 / 2017$, editada pelo presidente Michel Temer. Inicialmente, contextualiza-se a Medida Provisória 746 e sua conversão na Lei $n^{\circ}$ 13.415/17, popularmente denominada Lei do Novo Ensino Médio. Depois, demonstra-se a repercussão na sociedade e, principalmente, na estrutura curricular da educação básica. E, finalmente, ao observar as peculiaridades e conhecimentos exigidos para um aluno ingresso no curso de Direito, realiza-se uma análise das implicações que a reforma determinada pela referida lei trará para o ensino jurídico. A metodologia de abordagem é analítica e crítica. Adota conceitos jurídicos e doutrinários, verifica material normativo pertinente e ainda desenvolve crítica argumentativa acerca da supracitada lei no ensino jurídico do Brasil. Conclui-se a pesquisa com a preocupação de que conhecimentos prévios, de grande relevância para a formação do futuro advogado, estão sob grave ameaça com a lei.
\end{abstract}

\section{ABSTRACT}

The present research analyzes the reform in the High School of Brazil proposed by Act $n^{\circ} 13.415 / 2017$, edited by President Michel Temer. First, it contextualizes the Provisory Act 746 and its conversion in the Act $n^{\circ}$ 13.415/2017, popularly known as Law of New High School. Then, demonstrates its repercussion in the society and, mainly, in the curricular structure of the basic education. And, in the end, observing the peculiarities and knowledges required of a student admitted in Law Course, it analyzes the implications that the reform is going to cause to the legal education. The approach methodology is analytical and critical. It adopts legal and doctrinal concepts, verifies pertinent normative material, and develops argumentative criticism about the abovementioned law in Brazilian legal education. The research is concluded with the concern that previous knowledges, of much relevancy for the education of the future lawyer, are under serious threat by that law.

\footnotetext{
* Professor titular da Universidade de Fortaleza. Professor efetivo do mestrado em Saúde Coletiva da Universidade de Fortaleza e professor colaborador do Programa de Pós-Graduação (mestrado e doutorado) em Direito da Universidade de Fortaleza. Doutor em Sociologia pela Universidade Federal do Ceará. Mestre em Sociologia pela Universidade Federal do Ceará.

** Doutoranda em Direito Constitucional pela Universidade de Fortaleza. Mestre em Direito Constitucional pela Universidade de Fortaleza (UNIFOR). Bacharel em Direito pela Universidade Federal do Ceará

*** Bacharel em Direito pela Universidade de Fortaleza. Pós-graduanda em Direito Empresarial pela Universidade de Fortaleza. Mestre em Direito Constitucional nas Relações Privadas pela Universidade de Fortaleza.

${ }^{* * * *}$ Mestre em Computação Aplicada pela UECE/IFCE. Especialista em Ensino de Língua Portuguesa e Literatura. Bacharel em Letras pela Universidade Estadual do Ceará. Graduando em Direito na Faculdade Metropolitana da Grande Fortaleza. Assessor na Secretaria da Educação do Estado do Ceará. Professor em cursos de Pós-Graduação da Faculdade Ateneu e Universidade Federal do Ceará.
} 
PALAVRAS-CHAVE

Ensino Médio. Reforma. Lei No 13.415/2017. Implicações. Ensino Jurídico.

\section{KEYWORDS}

High School. Reform. Law $N^{o}$ 13.415/2017. Implications. Juridical Teaching.

\section{SUMÁRIO}

Introdução. 1 A contextualização e a criação da lei n ${ }^{\circ} 13.415$ de 2017. 22 o ensino jurídico no brasil. 3 As implicações lei no 13.415/17 no ensino jurídico. Conclusão. Referências.

\section{INTRODUÇÃO}

Inicialmente, ressalta-se que a educação é imprescindível para o desenvolvimento humano dos indivíduos, razão pela qual ela deve se dar de maneira a explorar vários setores de aprendizagem para que os estudantes sejam capacitados a utilizar o que foi apreendido nas diversas situações do cotidiano e na vida profissional.

Nesse sentido, considera-se que o direito à educação é um direito fundamental disposto em Constituições de inúmeras nações do mundo com o desiderato de garantir um ensino que alcance a todos da sociedade. No Brasil, tal direito é preconizado no artigo $6^{\circ}$ da Constituição Federal de 1988, encontrando-se no rol de direitos sociais previstos na referida Lei Maior.

Sabe-se que a educação envolve desde atos mais simples, como escrever o próprio nome, até lições mais complexas, como as moléculas existentes num copo de água. No ensino primário é ensinado aos alunos conteúdos elementares e, à medida que os estudantes vão aprimorando-se e avançando o conhecimento, matérias que exigem uma maior dedicação dos discentes vão sendo implementadas.

Destaca-se que, no Brasil, para a entrada dos indivíduos nas faculdades e universidades são realizados testes de admissão, os quais, a depender da Instituição, são realizadas provas de vestibular, ou é utilizado o resultado obtido no Exame Nacional do Ensino Médio (ENEM), sendo este último um exame realizado pelo Governo Federal com o fito de averiguar o desempenho dos alunos com escolaridade básica, o qual vem sendo utilizado como critério de seleção para a entrada no ensino superior por cerca de 500 universidades deste país, segundo dados do Ministério da Educação.

As avaliações supracitadas são bastante rigorosas e incluem diversas disciplinas, dentre as quais se pode citar biologia, química, história, geografia, português, literatura, língua estrangeira, matemática e física. Então, observa-se que, no Ensino Médio, período estudantil anterior ao ingresso do aluno nas faculdades e universidades, o ensino é direcionado para as referidas matérias a fim de possibilitar a aprovação dos alunos nos testes de seleção para o Ensino Superior, o qual viabilizará a formação profissional dos cidadãos.

Em 22 de setembro de 2016, o presidente Michel Temer editou a Medida Provisória 746. Em fevereiro de 2017, após aprovação no Congresso Nacional, a MP foi convertida na Lei $\mathrm{n}^{\mathrm{o}} 13.415$, de 16 de fevereiro de 2017. Dentre outras coisas, ela altera as Leis $\mathrm{n}^{\text {os }}$ 9.394, de 20 de dezembro de 1996, que estabelece as diretrizes e bases da educação nacional, e 11.494, de 20 de junho 2007, que regulamenta o Fundo de Manutenção e Desenvolvimento da Educação Básica e de Valorização dos Profissionais da Educação, a Consolidação das Leis do Trabalho CLT, aprovada pelo Decreto-Lei $\mathrm{n}^{-} 5.452$, de $1^{\text {o }}$ de maio de 1943, e o Decreto-lei no 236 , de 28 de fevereiro de 1967; revoga a Lei $\mathrm{n}^{\mathrm{o}} 11.161$, de 5 de agosto de 2005; e institui a Política de Fomento à Implementação de Escolas de Ensino Médio em Tempo Integral.

Dessa forma, a Lei $\mathrm{n}^{\circ}$ 13.415/17 prevê uma nova sistematização para o Ensino Médio, determinando que se passa a considerar o ensino 
dos conteúdos de educação física, filosofia e sociologia nesse período da educação, ou seja, não mais como componentes curriculares obrigatórios, além de impor a obrigatoriedade apenas das disciplinas de português e matemática e conhecimento do mundo físico e natural e da realidade social e política, especialmente da República Federativa do Brasil. Assim, o governo argumenta que a proposta de reforma do Ensino Médio almeja priorizar as necessidades individuais de cada aluno, bem como assemelharse aos currículos de outros países do mundo (BRASIL, 2016).

Ainda segundo o governo, essas mudanças propiciarão aos estudantes, ao concluírem o Ensino Médio, um conhecimento diferenciado, estando aptos a desenvolverem determinadas matérias e outras não, o que provocará consequências nas aulas ministradas pelos docentes da graduação quando esses estudantes ingressarem no Ensino Superior.

No entanto, faz-se necessário ter consciência de que, apesar do Nível Superior da educação ser direcionado para determinados assuntos, é imprescindível que os estudantes obtenham uma base de conhecimento que consolidará o que for aprendido nas universidades. Assim, a ênfase em algumas disciplinas específicas e a exclusão de determinadas matérias poderão resultar em deficiências na aprendizagem necessária para os cursos de graduação.

Nesse diapasão, faz-se o seguinte questionamento, o qual é respondido no decorrer desta análise: Quais os riscos para o Ensino Jurídico diante do provável ingresso de alunos com deficiências educacionais na formação básica, resultantes das alterações impostas pela Lei $\mathrm{n}^{\circ} 13.415$ de fevereiro de 2017 ?

A presente análise busca, inicialmente, contextualizar a Medida Provisória 746 editada por Michel Temer e sua conversão na Lei $\mathrm{n}^{\circ}$ 13.415/17, popularmente denominada Lei do Novo Ensino Médio. Em um segundo momento, intenciona-se demonstrar a repercussão na sociedade e, principalmente, na estrutura curricular da educação básica. E finalmente, observando-se as peculiaridades e conhecimentos exigidos para um aluno ingresso no curso de Direito, é realizada uma análise das implicações que a reforma determinada pela referida lei trará para o ensino jurídico, uma vez que conhecimentos prévios de grande relevância para a formação do futuro advogado estão sob graves ameaças de serem suprimidos do currículo do Ensino Médio, com a lei.

Apresenta-se, desse modo, uma pesquisa de conteúdo teórico (bibliográfica) por meio de obras que tratam diretamente e indiretamente do assunto estudado. Também é considerada analítica, quanto à obtenção de resultados, e qualitativa, quanto à abordagem. Diz-se ainda que a pesquisa é descritiva, uma vez que busca descrever, explicar, classificar, esclarecer e interpretar a medida observada. Além de exploratória, pois terá como objetivo a compreensão dessa temática através de conhecimentos relacionados ao Ensino Superior, mais especificamente da educação jurídica com o Ensino Médio.

O presente estudo demonstra-se pertinente para compreensão dos riscos ao ensino jurídico desenvolvido nas universidades e faculdades brasileiras, trazidos pela reforma do Ensino Médio e pela perspectiva de uma formação deficiente de futuros acadêmicos de Direito.

Desta feita, no desenvolvimento propriamente dito, realiza-se uma explanação do que dispõe a Lei $n^{\circ} 13.415$ de 16 de fevereiro de 2017, pormenorizando as modificações que ela trará ao Ensino Médio, explicitando as proposições positivas e as negativas oriundas da mudança na legislação e explanando as críticas direcionadas a ela.

Sucede-se com a caracterização do ensino jurídico no Brasil, sendo demonstrado como ele se dá e quais habilidades e saberes ele requer dos estudantes como base fundamental de 
conhecimento. Em seguida, antes da conclusão, elucida-se as implicações que a mencionada reforma no Ensino Médio pode trazer para o ensino jurídico aplicado nas instituições de Ensino Superior.

\section{A CONTEXTUALIZAÇÃO E A CRIAÇÃO DA LEI No 13.415 DE 2017}

No dia 22 de setembro de 2016, o presidente do Brasil, Michel Temer, editou a Medida Provisória número 746 , ato presidencial com prazo de 120 (cento e vinte dias) para ser convertida em lei mediante a aprovação do Congresso Nacional, de modo que caso não houvesse ocorrido a sua aprovação, ela perderia sua eficácia nos termos do artigo 62 da Constituição Federal de 1988.

O processo ocorreu sob muitas críticas de vários setores da sociedade, principalmente os setores diretamente relacionados à educação, tais como sindicatos de professores, sindicato dos trabalhadores da educação, universidades, Secretarias Estaduais de Educação e, até mesmo, do Conselho Nacional de Educação. A perspectiva da reforma do Ensino Médio ocorrer por meio de uma medida provisória causou grande polêmica. Enquanto o atual governo defendia, dentre outras coisas, o aumento da carga horária, criação de escolas de educação integral, flexibilização do currículo e autonomia para os estados, as críticas alertavam para as condições nas quais cada uma delas estaria embasada.

Vale destacar que a comunidade escolar mantém a crítica sobre a mudança, pois alega que não houve diálogo e o devido debate sobre a proposta. Deixando de considerar as opiniões de estudantes, professores e pesquisadores do tema. Além da forma açodada como todo o processo ocorreu, sem o tempo necessário para uma discussão ampla e democrática, justamente o oposto da alteração que iniciou com uma Medida Provisória e findou-se com a aprovação da lei.

Dentre as mudanças trazidas pela referida lei, pode-se mencionar o aumento da carga horária anual para 1.400 (um mil e quatrocentos) horas a serem aplicadas em turno integral, bem como a composição do currículo escolar pela Base Nacional Comum Curricular e por itinerários formativos específicos a serem definidos pelos sistemas de ensino dos estados, devendo ter ênfase nas áreas de linguagens, matemática, ciências da natureza, ciências humanas e formação técnica profissional. Os testes de ingresso no Ensino Superior passam a ser regidos pela referida base curricular, sendo excluídos os conteúdos da formação técnica profissional.

Salienta-se que a Base Nacional Comum Curricular é um documento que norteia as políticas públicas educacionais e que estabelece quais conteúdos disciplinares deverão ser ensinados aos estudantes brasileiros, estando ela ainda em fase de elaboração (BRASIL, 2016).

Além das mutações supramencionadas, merecem destaque as modificações trazidas pela medida em comento no sentido de retirar a obrigatoriedade das disciplinas de educação física, filosofia e sociologia no Ensino Médio, bem como impor a obrigatoriedade, nesse período estudantil, somente das matérias de artes, português, inglês e matemática, o que difere bastante do modelo anterior, o qual estabelecia a obrigatoriedade de uma quantidade bem maior de disciplinas. $\mathrm{Na}$ verdade, os mais críticos alertam para que, com exceção destes últimos quatro componentes citados, todos os outros passam a configurar como não obrigatórios, podendo estar diluídos e representados por estudos dos tópicos, atividades e conhecimentos, sem um componente curricular específico.

Ademais, ressalta-se que quanto à língua estrangeira, passou a ser obrigatório o ensino do inglês nos três anos do Ensino Médio, ficando ao cargo do interesse de cada escola oferecer outros 
idiomas que poderão ser cursados em caráter facultativo. Tal proposta distingue-se do currículo anterior, o qual não especifica qual língua estrangeira deve ser lecionada, determinando apenas que haja o ensino de um idioma o qual seria livremente escolhido.

Outra observação a ser feita é que a Lei $n^{\circ}$ 13.415/17 reafirma um currículo do Ensino Médio flexível, sendo dividido em dois, em que a primeira parte terá disciplinas fixas e obrigatórias e a segunda conterá matérias optativas que serão escolhidas pelo aluno, podendo ele formar uma grade de acordo com as suas aspirações profissionais (BRASIL, 2017).

Observa-se que a reforma aprovada pelo governo federal traz alguns aspectos positivos e outros negativos. Pode-se dispor que o aumento da carga horária poderá possibilitar um maior aproveitamento do ensino escolar pelos estudantes, os quais terão um acompanhamento maior pelos docentes, todavia, tal sistema pode encarecer bastante os custos na educação, sofrendo, assim, tanto os alunos de escolas privadas que terão que desembolsar uma quantia maior para pagar as mensalidades dos colégios, como os alunos de escolas públicas, que poderão sofrer com a possível diminuição de vagas, fato que ensejará a desigualdade ao permitir que alguns indivíduos sejam matriculados nas escolas públicas e outros não.

Também se percebe que o método proposto de flexibilizar a grade curricular e dar autonomia aos estudantes para escolherem as disciplinas, de acordo com suas aspirações profissionais pode ser precário, tendo em vista o risco de que os discentes escolham não cursar determinadas disciplinas por julgarem que elas não seriam necessárias, quando, na verdade, elas seriam de extrema necessidade para a sua formação profissional, o que poderá causar uma deficiência no aprendizado que será sentida pelo aluno quando ele ingressar na universidade.

Cita-se ainda que a remoção da obrigatoriedade das disciplinas de filosofia e sociologia possibilita que os alunos abandonem o estudo dessas matérias, o que retira a capacidade argumentativa e crítica dos cidadãos, essenciais para um Estado Democrático como o Brasil.

É imperioso mencionar que as modificações no Ensino Médio propostas pela Medida Provisória 746 de 22 de setembro de 2016, reafirmadas a partir de sua conversão na lei $n^{\circ}$ 13.415/17, geraram várias repercussões na sociedade, de modo que parte da população brasileira tem se mostrado contrária a elas, havendo, contudo, cidadãos que entenderam pela pertinência e necessidade da concretização dessas mudanças.

A Faculdade de Educação da Universidade de São Paulo (2016), insigne instituição deste país, divulgou uma nota de repúdio à edição da então medida provisória $\mathrm{n}^{\mathrm{o}} 746 / 16$, trazendo diversas razões que corroboram com a não concordância do ato presidencial:

[...] a total ausência do diálogo, fundamentação e bases empíricas que deveriam caracterizar uma reforma dessa monta; fere a garantia legal de uma formação de base comum a todos e contraria o sentido que a Lei de Diretrizes e Bases da Educação - Lei 9.394/96 confere ao Ensino Médio, isto é, como etapa da Educação Básica; reforça a desigualdade de oportunidades educacionais ao segmentar o currículo e deixar a critério dos sistemas de ensino a decisão da oferta das ênfases ou áreas que poderão ser realizadas pelos estudantes, impedindo-lhes o acesso e a consolidação dos direitos básicos a conhecimentos imprescindíveis para o exercício pleno da cidadania e fomento à curiosidade intelectual, tão cara a todos; retira a obrigatoriedade dos componentes Arte, Educação Física, Filosofia e Sociologia impossibilitando a interação com distintos patrimônios culturais que alimentam e potencializam as formas de expressão, o pensar diferente e a compreensão das relações sociais, culturais e políticas que caracterizam a vida em sociedade; promove a desqualificação da formação de professores e professoras via o chamado "notório saber" que desconsidera as especificidades do conhecimento e suas áreas e que, sem o justo e necessário investimento em educação, 
ganham proporções aviltantes e acentuam a precarização da escola pública, da qualidade do ensino e da profissão docente.

No mesmo sentido, a professora do Núcleo de Avaliação Educacional da Faculdade de Educação da Universidade Federal do Ceará (UFC), Adriana Eufrásio Braga (2016), apontou críticas à medida, afirmando que é uma mudança brusca para ser executada num curto período de tempo e aduzindo que esta se trata de um retrocesso, pois os itinerários educativos de livre escolha dos estados podem ser limitados diante do que for oferecido por cada escola, o que não viabilizará a priorização dos interesses profissionais de cada aluno, já que estes escolherão as disciplinas de acordo com o que é oferecido pela sua instituição de ensino.

Apesar dessas críticas, há quem concorde com a reforma do Ensino Médio. Cláudia Costin (2016), professora visitante da Universidade de Harvard e ex-diretora de educação do Banco Mundial afirma que o atual modelo de ensino brasileiro é retrógrado e não se equipara com os sistemas dos outros países do restante do mundo:

O Brasil oferece 13 disciplinas no ensino médio e essa não é a experiência internacional. O nosso modelo é da época da ditadura e, aos poucos, foram introduzidas mais e mais disciplinas em uma carga horária pequena. Não tem como cobrir um currículo enciclopédico com um número de horas tão restrito.

O atual Ministro da Educação, José Mendonça Bezerra Filho (BRASIL, 2016), corrobora com o entendimento da professora Cláudia Costin, afirmando ele que todas as outras nações têm um ano de ensino de conteúdo comum e o restante das disciplinas são traçadas pelo próprio estudante, argumentando que a experiência brasileira de lecionar 13 (treze) disciplinas faz com que os alunos do Ensino Médio, ao não se identificarem com determinadas matérias, abandonem a escola.

Ainda é preciso ter ciência sobre as condições educacionais e sociais de ingresso no
Ensino Médio que nossos jovens apresentam. Configura-se como um risco real a preferência pelo itinerário de formação para o trabalho, por ser considerado por muitos como o mais prático e mais fácil dos itinerários, além da necessidade de ajudar financeiramente a família.

No entanto, essa escolha deve ser analisada com maior atenção, pois ao invés de escolher o itinerário que realmente tem interesse, pode ser guiado para o itinerário da formação profissional, ou por acreditar que é o único itinerário no qual terá sucesso acadêmico, tendo em vista as deficiências escolares trazidas do Ensino Fundamental, ou ainda pela necessidade de aumentar as chances de ingresso no mercado de trabalho para ajudar a aumentar a renda familiar.

Diante desse contexto, é possível constatar que a Lei $n^{\circ} 13.415$ de 2017 traz mudanças no Ensino Médio que representam uma profunda transformação na estrutura da educação brasileira, o que, por conseguinte, gerará uma mutação na metodologia de ensino e no currículo dos cursos de graduação deste país, haja vista que o novo tipo de formação dos alunos, enseja modificações nos conhecimentos adquiridos por estes no período antecedente ao ingresso nas universidades.

\section{O ENSINO JURÍDICO NO BRASIL}

O ensino jurídico é aquele realizado com o desiderato de efetivar a formação superior de profissionais entendedores e aplicadores das regras e princípios vigentes no ordenamento jurídico de um país, tendo como objeto de estudo a ciência do Direito, a qual estuda o dever ser e adentra na abstração ao visar regular o comportamento dos indivíduos da sociedade. Tal ensino empreende a educação de cidadãos que poderão atuar em diversas áreas, como na advocacia, promotoria, procuradoria, 
magistratura, magistério jurídico, cartorial, dentre outras.

O Direito, objeto de estudo do ensino jurídico, é uma ciência social aplicada, tendo em vista que examina as normas que regulam as relações sociais dos indivíduos, bem como as soluções dos problemas dos cidadãos da comunidade (MONTEIRO, 2001, p. 42).

Nesse diapasão, afirma-se que a origem do ensino jurídico no Brasil teve como fato propulsor o comparecimento de estudantes brasileiros, no período colonial, à Universidade de Coimbra, em Portugal. Então, um ano após a declaração da independência do Brasil, com a Assembleia Constituinte de 1823, foi aprovada a criação do ensino jurídico no Brasil, sendo este efetivamente instituído alguns anos mais tarde, em 1827, quando foi criado o Curso de Ciências Jurídicas e Sociais no Estado de São Paulo e em Olinda, no Estado de Pernambuco (BEZERRA, 2008, p. 62).

Daniela Mossini (2010, p. 76) aponta que, com a criação dos cursos de Direito no Brasil após a independência, objetivava-se formar um corpo de profissionais capacitados intelectualmente para conduzir o país nos campos políticos e jurídicos:

\begin{abstract}
Após a Independência, dentro do processo de emancipação política e cultural do Brasil, criou-se um novo cenário, como parte das exigências culturais e ideológicas de um Estado Nacional em formação. Não existia mais Metrópole e Colônia, mas sim campo e cidade. Assim é que os novos bacharéis, oriundos das classes dominantes (latifúndios e comércio), não mais precisariam transpor o oceano para ir às universidades da Europa. Procurava-se estabelecer, assim, a formação de uma elite intelectual brasileira capaz de guiar a nação jurídica e politicamente.
\end{abstract}

Faz-se mister enfatizar que o ensino jurídico corre o sério risco de se encontrar em desconexo com a realidade econômica e social, tendo em vista que ele precisa ser encarado de forma ampla, em consonância com o contexto social na qual está inserido, não podendo ser visto como um sistema positivo hermeticamente fechado e distante da realidade. Corroborando com essa ideia, dispõe Lyra Filho (1982, p.86) que é imperioso:

Reexaminar o Direito, não como uma ordem estagnada, mas como a positivação em luta, dos princípios libertadores, na totalidade social em movimento. O Direito, então, há de ser visto como um processo histórico. Direito (...) não é uma coisa feita, perfeita e acabada (...)

Não se pode confundir ensino jurídico com o mero estudo de leis e atos normativos, pois a ciência do Direito precisa ser um instrumento simbiótico entre a teoria e a prática. A metodologia adotada pelos professores do ensino jurídico precisa conciliar estes dois fatores supracitados, bem como necessita ser dotada de dinamismo, com o fito de estimular os alunos a terem um maior interesse acadêmico.

Vale ressaltar o disposto na Resolução CNE/CES n ${ }^{\circ}$ 9, de 29 de setembro de 2004, do Ministério da Educação, que norteia o currículo do curso de graduação em direito, estabelecendo que:

Art. $3^{\circ}$. O curso de graduação em direito deverá assegurar, no perfil do graduando, sólida formação geral, humanística e axiológica, capacidade de análise, domínio de conceitos e da terminologia jurídica, adequada argumentação, interpretação e valorização dos fenômenos jurídicos e sociais, aliada a uma postura reflexiva e de visão crítica que fomente a capacidade e a aptidão para a aprendizagem autônoma e dinâmica, indispensável ao exercício da Ciência do Direito, da prestação da justiça e do desenvolvimento da cidadania.[...]

Art. $5^{\circ} \mathrm{O}$ curso de graduação em Direito deverá contemplar, em seu Projeto Pedagógico e em sua Organização Curricular, conteúdos e atividades que atendam aos seguintes eixos interligados de formação:

I - Eixo de Formação Fundamental, tem por objetivo integrar o estudante no campo, estabelecendo as relações do Direito com outras áreas do saber, abrangendo dentre outros, estudos que envolvam conteúdos essenciais sobre Antropologia, Ciência 
Política, Economia, Ética, Filosofia, História, Psicologia e Sociologia.[...] (BRASIL, 2004).

Observado o disposto na Resolução CNE/CES $n^{\circ}$ 9, de 29 de setembro de 2004, o professor não pode se ater à mera exposição do direito positivado, como a leitura de leis ou atos normativos, precisando ele ir além, tendo em vista que o estilo de aula expositiva não é o mais vantajoso para os alunos, pois desenvolve um aluno inerte, passivo, que fica apenas sentado na sala de aula absorvendo, ou não, a maior quantidade de informações possíveis, sem se questionar o motivo das mesmas ou como se chegou a elas.

Reforça esse ponto de vista o que expõe Lôbo (1996, p. 10-11), trata da necessidade de se buscar realizar uma interdisciplinaridade, indo além do saber dogmático do direito, tem importante contribuição para a formação do estudante de direito e sua profissionalização. Ainda segundo esse autor, o conteúdo a ser estudado pelo acadêmico de direito divide-se em três partes: a primeira, denominada de parte fundamental e reflexiva-crítica; a segunda, nomeada de parte profissionalizante ou técnicajurídica, e; a terceira e última parte, chamada de prática.

Para Gajardoni (2001), não há o desenvolvimento de um raciocínio crítico, a capacidade argumentativa do discente não é priorizada, a qual deveria ser uma das principais preocupações da didática adotada no ensino jurídico, tendo em vista que o desenvolvimento de discentes ativos é essencial para a boa aplicação do Direito.

Ao revés de apresentarem uma formação humanística consistente, habilitando o profissional para o entendimento das transformações sociais políticas e econômicas, possibilitando-lhe um distanciamento crítico, uma conscientização de suas funções, nessa sociedade em constante mutação, marcada pelo descompasso entre igualdade jurídicoformal e igualdade econômica, as faculdades de direito ainda zelam por uma formação normativista- formalista de seus alunos, preocupadas com um ensino eminentemente técnico, firmado em proposições e tipificação de condutas sociais à norma posta, desprezando qualquer tipo de conhecimento extra ou metajurídico e interação com outras áreas do conhecimento. (GAJARDONI, 2001, p. 60-61)

É necessário que os alunos sejam capazes de trazer aquilo que é exposto em sala de aula para a sua vida prática, pois, ao se fazer uma relação com a realidade concreta, depreende-se um maior proveito na aprendizagem e internalização da matéria exposta. Dispõe nesse sentido Gasparin (2005, p. 6): “(...) o levantamento e o questionamento do cotidiano imediato e remoto de um grupo de educandos conduzem à busca de um suporte teórico que desvende, explicite, descreva e explique essa realidade".

Ressalte-se que o professor do ensino jurídico precisa ser capaz de alcançar um meio termo entre a teoria e a prática, pois a formação do discente jurídico não pode ser fundamentada apenas no Direito posto e teórico, além de que não pode ser pautada apenas na prática forense. Ambos precisam caminhar juntos, para possibilitar a formação de profissionais completos e aptos a colocarem em prática toda a teoria aprendida ao longo da graduação:

\begin{abstract}
A expansão do ensino jurídico ocorrida, no Brasil a partir dos anos 90, trouxe para o ensino um grande número de profissionais, em grande parte sem preparação prévia e sem reflexão sobre a própria prática. A mera reprodução da tradição de ensino formal transforma o direito em algo estanque e morto, porque ausente dos problemas vivos, cujo enfrentamento é crucial para a sociedade e para a legitimação do próprio direito. (CADERNOS FGV DIREITO RIO, 2010, p. 4)
\end{abstract}

Afere-se que a conjugação proporcional da teoria com a aplicabilidade em casos concretos é de fundamental importância no ensino jurídico, haja vista a dificuldade enfrentada pelos discentes do curso de Direito, os quais se deparam, no início do curso, com disciplinas complexas e abstratas. O conhecimento prévio de matérias humanísticas 
e de cunho reflexivo são indispensáveis, pois asseguram o desenvolvimento de uma base reflexiva essencial para a boa formação do estudante.

Depreende-se do exposto que o ensino jurídico brasileiro está passando por uma crise, na qual medidas precisam ser tomadas com o fito de reverter tal quadro. E este cenário de crise, com o ingresso de estudantes com deficiência em disciplinas como história, filosofia, sociologia e sem o desenvolvimento da sua reflexão e crítica ainda na educação básica, corre sério risco de causar um aprofundamento dos problemas relacionados ao ensino do direito e a formação completa do profissional da advocacia.

\section{AS IMPLICAÇÕES LEI No $13.415 / 17$ NO ENSINO JURÍDICO}

Dentre as várias mudanças na sistematização do Ensino Médio da supracitada lei, algumas merecem destaque no estudo ora em comento pelo fato de implicarem maiores repercussões no ensino jurídico brasileiro. Podese citar a flexibilização da grade curricular, de forma que, consoante o já exposto, os próprios alunos terão o condão de escolherem as disciplinas que irão cursar de acordo com suas preferências. Com isso, há o sério risco de eles deixarem de cursar matérias importantes para a sua formação humanística e profissional, o que irá repercutir no futuro, quando estes entrarem no ensino superior, surgindo, porventura, uma possível carência em diversas disciplinas.

Outra mudança que merece enfoque, pois terá maior repercussão no ensino jurídico brasileiro diz respeito à remoção da obrigatoriedade das disciplinas de filosofia e sociologia. Ao excluir a obrigatoriedade destas matérias da grade curricular do ensino médio, surge uma consequência bastante negativa, qual seja: o comprometimento da capacidade argumentativa e crítica dos cidadãos.

Nesta senda, com as mudanças advindas da Lei $\mathrm{n}^{\mathrm{o}}$ 13.415/17, o discente chegará ao ensino superior sem uma formação humanística adequada, tendo em vista que as disciplinas que desenvolvem uma consciência humanizada nos estudantes, como as artes e filosofia, poderão não ser abordadas ao longo do Ensino Médio, fato que possivelmente resultará em uma carência forte nos alunos no que tange à formação e ao desenvolvimento de sua capacidade argumentativa, bem como de seu raciocínio crítico.

Em uma análise mais crítica, a educação superior tem sua autonomia universitária negada, pois a lei estabelece que os cursos de graduação deverão, em seus processos seletivos, considerar competências e habilidades definidas na Base Nacional Comum Curricular, como expresso no parágrafo terceiro do inciso segundo do artigo 44 do capítulo IV, da Educação Superior. Assim, há não só o risco de empobrecimento curricular do Ensino Médio, mas também que tal empobrecimento contamine o currículo acadêmico dos cursos de nível superior.

Nesse contexto é que se pode falar em um retrocesso advindo das alterações implementadas pela Lei do Novo Ensino Médio. Diante da fragilidade no que se refere à capacidade crítica e argumentativa do estudante do ensino superior, tem-se o fato de que ele poderá ficar distante da realidade a qual o cerca, ou seja, ficará afastado da contextualização social na qual a ciência do Direito estudada por ele está imersa.

A realidade social advém de um processo histórico, sendo por isso necessária a formação humanística do discente de Direito. Ao tirar a obrigatoriedade das disciplinas como sociologia e filosofia do Ensino Médio, o aluno chegará ao ensino superior com uma carência em tal formação. Sendo certo que terá de adquiri-la mais cedo ou mais tarde, o ideal não seria ter esse 
contato apenas no ensino fundamental e na graduação, mas sim solidificá-la ao longo da vida estudantil. Logo, o mais acertado é amadurecer algo que já fosse existente e que viesse sendo construído ao longo de todo o período escolar.

Destaque-se que o Direito não pode ser visto apenas como um curso técnico, como destacado anteriormente tanto na Resolução CNE/CES $n^{\circ} 9$, estabelecendo as diretrizes do curso de Direito, quanto na crítica de Gardajoni, anteriormente citada. Faz-se imperioso haver uma interdisciplinaridade, no âmbito do ensino do Direito, porque só assim faz-se possível inserir a teoria jurídica em meio a um contexto social, o que é providencial para uma compreensão eficaz da ciência do Direito. Vale destacar a seguinte afirmação de Lôbo:

A interdisciplinaridade, na dimensão externa ao saber dogmático jurídico, enlaça-se com matérias que contribuem para a formação do profissional de direito, notadamente estimuladoras da reflexão crítica e da atuação político-institucional, que a sociedade cada vez mais dele reclama. Assim, a interessante abertura para as Ciências Sociais, Humanas, Políticas, para a Filosofia, incluindo as perspectivas lógica e ética, para a Psicologia, para a Informática, para a Ciência da Linguagem (LÔBO, 1996, p. 10-11).

Há uma intrínseca relação entre justiça, moral e ética na concretização do direito. Assim, busca-se o bom convívio social a partir de valores e princípios que devem ser discutidos e lançados suas bases teóricas desde a formação básica dos educandos. Tendo em vista as dificuldades já existentes no ensino do direito, ainda delegar à formação acadêmica a obrigação de propiciar o aprendizado de conteúdos abordados no ensino médio nas disciplinas da Área do Conhecimento de Ciências Humanas é lotear ainda mais a formação dos estudantes.

Assim, o Direito não pode ser entendido e estudado de forma isolada, precisando o estudante ser capaz de fazer uma ligação da teoria estudada com a realidade que o cerca. Ocorre que, para ser capaz de fazer essa relação, faz-se mister que ele seja dotado de uma consciência crítica, o que não será mais priorizado no Ensino Médio com a nova estrutura curricular.

A exemplo, cita-se o que atesta Reale (2007) ao defender o ensino da Sociologia nos cursos de Direito:

\begin{abstract}
Em linhas gerais, porém, pode-se dizer que a Sociologia tem por fim o estudo do fato social na sua estrutura e funcionalidade, para saber em suma, como os grupos humanos se organizam e se desenvolvem, em função dos múltiplos fatores que atuam sobre as formas de convivência.

Com essa noção elementar que nos situa no limiar de um grande tema, já podemos ver que a Sociologia não tem por objetivo traçar normas ou regras para o viver coletivo, mas antes verificar como a vida social comporta diversos tipos de regras, como reage em relação a elas, nestas ou naquelas circunstâncias etc. [...]

Desnecessário é encarecer a importância da sociologia para o jurista ou para o legislador, sendo as suas conclusões indispensáveis a quem tenha a missão de modelar os comportamentos humanos, para considerá-los lícitos ou ilícitos (REALE, 2007, 167).
\end{abstract}

Sabedores da realidade, da falta de espaço nos currículos acadêmicos para a existência da disciplina de Sociologia na graduação em direito, apresenta-se agora a realidade da clara exclusão desse aprendizado também no ensino médio. Daí resulta a inquietação provocada pela afirmação de Reale, quando confrontada com as mudanças trazidas pela lei a respeito de como o jurista vai analisar e compreender de forma proficiente a licitude dos atos humanos em sociedade.

Vale ressaltar que uma reflexão crítica e uma formação humanística são essenciais no sistema educacional brasileiro, de modo geral, mas, principalmente, no que se refere aos cursos de Direito, pois o ensino jurídico visa, primordialmente, desenvolver a capacidade reflexiva e argumentativa do discente. Nesta senda, o verdadeiro objetivo dos cursos jurídicos não consiste no estudo sistemático dos institutos e 
normas, mas sim no preparo, no desenvolvimento e no treinamento do raciocínio jurídico.

Essa carência no conhecimento de humanidades, resultado das mudanças ocasionadas pela Lei $\mathrm{n}^{\circ} 13.415 / 17$, fará com que os professores dos cursos de graduação tenham que supri-la. Por consequência, a metodologia adotada, bem como o currículo da graduação provavelmente precisarão ser mudados com o fito de se adaptarem ao novo perfil de alunos que chegarem ao ensino superior após a implementação de tais mudanças.

Nesta esteira, destaca-se a importância do uso de metodologias participativas entre o discente e docente na busca de um melhor aproveitamento da aprendizagem, tendo em vista que a tradicional aula expositiva fica muito aquém da formação de qualidade, conforme passagem de Godoy:

Pouca participação do aluno em função da comunicação unilateral característica desta técnica de ensino. Considera a classe como um grupo uniforme, não levando em conta o fato de que os alunos possuem estilos de aprendizagem diferenciados. Não considera o fato de que muitos ou alguns alunos não possuem os conhecimentos prévios necessários. Não favorece o desenvolvimento das habilidades intelectuais mais complexas (aplicação, análise, síntese e julgamento) que levam o aluno a pensar sobre o que aprendeu. Não possibilita que o professor realize a função de avaliação acompanhando o aprendizado (ou não) do aluno. Às vezes cria o hábito de os alunos estudarem através de suas anotações não recorrendo à bibliografia indicada pelo professor (GODOY, 1997, p. 78-79).

Esse desafio de adaptação do ensino superior já vinha sendo colocado em pauta com o fito de aperfeiçoar os cursos de graduação, corroborando com essa ideia de Alexandre de Paula Franco:

Está colocado um desafio sem precedentes para os docentes do ensino superior, diante do desafio de garantir uma formação acadêmica substancial baseada na intelectualidade e na perspectiva investigativa, e concomitantemente repensar a organização dos cursos e as possíveis formas de melhoria do impacto dos egressos da educação superior na sociedade (FRANCO, 2008, p.58).

Além disso, cita-se ainda que este novo perfil de aluno do ensino jurídico não é favorável para o funcionamento pleno e efetivo da democracia, haja vista que a capacidade argumentativa e o raciocínio crítico são essenciais para o fortalecimento do Estado Democrático brasileiro. A ausência de importância que é dada ao desenvolvimento do raciocínio crítico pode ser interpretada como uma medida que se remete às práticas do período de ditadura militar no Brasil, uma vez que a ausência da capacidade argumentativa nos cidadãos poderia representar uma verdadeira ameaça ao sistema. Dispondo nesse sentido tem-se Martha Nussbaum:

Se o que se deseja é um conjunto de trabalhadores obedientes tecnicamente treinados para executar os projetos de elites que visam o investimento externo e o desenvolvimento tecnológico, a liberdade de pensamento dos alunos é perigosa. O raciocínio crítico será desestimulado (...) (NUSSBAUM, 2015, p. 21).

Destarte, uma educação de qualidade precisa ser capaz de viabilizar e efetivar um aprendizado ativo, no qual, o aluno em formação educacional, torne-se apto a desenvolver um pensamento crítico. Neste sentido, cita-se Gina Pompeu e Natércia Sampaio defendendo que:

[...] exercício adequado da racionalidade, que não é o mero ator a encenar um texto já escrito sob a batuta de um severo diretor: o merecedor, em razão da vontade divina ou da ordem cósmica. A perspectiva do homem como o ator, diretor e autor do espetáculo chamado vida é a chegada de uma longa caminhada, durante a qual se vai reconhecendo a sua agência como indivíduo, como ser político, econômico e ético (POMPEU; SAMPAIO, 2014, 932-933).

Faz-se necessária uma democratização educacional que permita o desenvolvimento de um raciocínio crítico por parte do cidadão como forma de efetivação do direito fundamental à liberdade de expressão e de pensamento, direitos 
estes que correspondem a um verdadeiro corolário democrático. Sendo assim, uma educação fundamentada na reflexão argumentativa representa o ponto central de uma educação posta numa sociedade democrática. Nesta senda, a reforma do sistema educacional baseada em um ambiente democrático se faz providencial, almejando o exercício pleno e efetivo da democracia. (VASCONCELOS, 2014, p. 85).

Depreende-se do exposto que as mudanças advindas da Lei $\mathrm{n}^{\mathrm{o}} 13.415$, de 16 de fevereiro de 2017 implicam em consideráveis alterações no ensino jurídico brasileiro, em virtude da nova sistematização dada ao Ensino Médio, principalmente com a remoção da obrigatoriedade de disciplinas como sociologia e filosofia, as quais representam requisitos basilares à capacidade argumentativa e raciocínio crítico, contribuintes ativas à formação humanística do indivíduo e indispensáveis para a capacitação do profissional do Direito.

\section{CONCLUSÃO}

A educação constitui condição imprescindível ao desenvolvimento humano, sendo por isso considerada um direito fundamental, essencial para a formação do cidadão. O direito social à educação está previsto na Constituição Federal de 1988, em seu artigo 205.

O ingresso dos indivíduos no ensino superior se dá por meio de testes de admissão, como o Exame Nacional do Ensino Médio (ENEM), com o fito de analisar o desempenho dos alunos. Diante da rigorosa avaliação a qual os alunos são submetidos, faz-se mister que o ensino básico escolar seja voltado para preparar os estudantes, para assim permitir que estes tenham uma formação profissional satisfatória.

No dia 22 de setembro de 2016, o presidente Michel Temer editou a Medida Provisória 746, com o escopo de dar uma nova sistematização ao
Ensino Médio Brasileiro. Em 16 de fevereiro de 2017, foi aprovada a lei $n^{\circ} 13.415$ que altera toda a estrutura do Ensino Médio no Brasil. Dentre as mudanças, merece destaque a retirada da obrigatoriedade do ensino de educação física, filosofia e sociologia. Destaque que um dos argumentos utilizados pelo Governo para justificar tal medida que propõe a reforma no Ensino Médio foi a tentativa de priorização das necessidades pessoais de cada estudante, além de visar uma maior semelhança e uniformização curricular com os sistemas educacionais de outras nações.

Uma das grandes problemáticas dessa proposta do Governo é o fato de que com as mudanças advindas da lei supramencionada, o ensino ficará direcionado para determinados assuntos específicos, o que pode resultar em uma deficiência no aprendizado que se faz essencial para o ingresso no ensino superior, haja vista que como qualquer mudança, tem seus prós e contras. É nesta esteira que se questiona quais consequências as mudanças trazidas pela referida lei no ensino jurídico brasileiro.

O ensino jurídico tem como objeto de estudo a ciência do Direito, e teve início no contexto social brasileiro com o fito de formação de um corpo profissional capacitado, para assim ter o condão de comandar o país após a sua independência. Ressalte-se ainda que é essencial ao ensino jurídico estar de acordo com a realidade social e econômica do contexto ao qual está implantado, sendo por isso errônea a ideia de que o ensino jurídico se resume ao simples estudo de leis e atos normativos, haja vista que ele vai muito além, pois não se resume a um curso técnico, bem como é providencial que haja a relação entre a teoria e a prática. Daí a importância que precisa se dar ao ensino socrático, no qual o aluno é ativo e participativo.

Depreende-se da flexibilização curricular uma possível precariedade profissional dos alunos, tendo em vista que os estudantes podem deixar de 
cursar disciplinas que considerem como não importantes para sua formação, o que poderá dar margem para problemas futuros, como dificuldade de acompanhamento ao longo do ensino superior, em virtude de uma falha formação educacional básica.

Faz-se imperioso ressaltar que com a retirada da obrigatoriedade de disciplinas como filosofia e sociologia, corre-se o risco de os alunos deixarem de dar a devida importância para tais matérias, o que resulta em um problema para a formação e efetivação da capacidade crítica e argumentativa do indivíduo, aspectos essenciais para o exercício pleno e efetivo da democracia.

A formação humanística do aluno também corre o risco de ficar comprometida com as mudanças advindas da medida provisória, com isso, tal carência terá de ser suprida ao longo da graduação, o que pode resultar na necessidade de mudanças metodológicas com o fito de se adaptar à nova realidade dos alunos.

Depreende-se então que a lei 13.425 poderá trazer inúmeras mudanças ao ensino jurídico brasileiro, principalmente no que diz respeito ao desenvolvimento da capacidade crítica e argumentativa do discente, bem como à sua formação humanística. Dessa forma, faz-se mister ressaltar a importância destes aspectos para a capacitação profissional do estudante, bem como para seu papel como cidadão ativo na sociedade democrática brasileira.

\section{REFERÊNCIAS}

BRASIL. Constituição (1988). Constituição da república federativa do Brasil. Brasília: Senado, 1988.

ENEM-Apresentação. [ca. 2016]. Disponível em: <http://portal.mec.gov.br/en em-sp2094708791>. Acesso em: 24 out. 2016.

Estrutura curricular é a base do Novo Ensino Médio, reforça secretário de educação.[2016] Disponível em: <http://www.brasil.gov.br/educacao/2016/09/estrutu ra-curricular-e-a-base-do-novoensino-medio-reforca-secretario-de-educacao>. Acesso em: 24 out. 2016.

. Lei $\mathrm{n}^{\circ} 13.145$, de 16 de fevereiro de 2017. Altera a Leis $\mathrm{n}^{\circ}$ 9.394, de 20 de dezembro de 1996, que estabelece as diretrizes e bases da educação nacional. Disponível em : <http://www.planalto.gov.br/ccivil_03/_ato2015-2018/2017/lei/113415. htm>. Acesso em: 17 fev. 2017.

Medida Provisória $n^{\circ} 746$, de 22 de setembro de 2016. Institui a Política de Fomento à Implementação de Escolas de Ensino Médio em Tempo Integral, altera a Lei $n^{\circ}$ 9.394, de 20 de dezembro de 1996, que estabelece as diretrizes e bases da educação nacional, e a Lei n ${ }^{\circ} 11.494$ de 20 de junho 2007, que regulamenta o Fundo de Manutenção e Desenvolvimento da Educação Básica e de Valorização dos Profissionais da Educação, e dá outras providências. Diário Oficial da União, Brasília, DF, 22 de setembro de 2016.

. Ministério da Educação. Resolução CNE/CES N 9, DE 29 de setembro de 2004. Institui as Diretrizes Curriculares Nacionais do Curso de Graduação em Direito e dá outras providências. Disponível em: <http://portal.mec.gov.br/cne/arqui_vos/pdf/rces09_04.pdf〉. Acesso em: 15 set. 2016.

BRAGA, Adriana Eufrásio. Especialistas fazem ressalvas a Reforma do Ensino Médio. 23 set. 2016. Fortaleza: Jornal $O$ Povo. Entrevista concedida ao Jornal O Povo. Disponível em: 
<http://www.opovo.com.br/app/opovo/cotidiano/2016/09/23/notici

asjornalcotidiano,3660449/especialistas-fazem-ressalvas-a-reforma-do-ensino-medio.shtml>. Acesso em: 24 out. 2016.

BEZERRA, Roberta Teles. Ensino jurídico e direitos fundamentais. Fortaleza: Expressão, 2008.

BEZERRA FILHO, José M. Mendonça Filho diz que críticas à proposta de reforma no Ensino Médio são ideológicas. 26 setembro de 2016. Recife: Diário de Pernambuco. Entrevista concedida a Tércio Amaral. Disponível em: <http://www.diariodepernambuc o.com.br/app/noticia/politica/2016/09/26/interna_politica,666792/ha-muita-grita-por-falta-deinformacao-e-ha-muita-grita-por-convenienc.shtml>. Acesso em: 25 out. 2016.

CADERNOS FGV DIREITO RIO. Educação e Direito. Rio de Janeiro: Fundação Getúlio Vargas, v. 3, fev. 2009. Disponível em: < http://bibliotecadigital.fgv.br/ dspace/bitstream/handle/10438/10400/Cadernos\%20FGV\%20Direito\%20Rio\%20-\%20

Vol.\%203.pdf?sequence=1\&isAllowed=y >. Acesso em: 11 nov. 2016.

COSTIN, Claudia. Proposta de reforma do Ensino Médio divide especialistas; saiba o que muda. 22 set. 2016. Curitiba: Jornal Gazeta do Povo. Entrevista concedida a Sharon Abdalla e Denise Drechsel. Disponível em: <http://www.gazetadopo vo.com.br/educacao/proposta-de-reforma-do-ensino-mediodivide-especialistas-saiba-o-que-muda-3sb7aagi3vo1mtks21zdwlr4w>. Acesso em: 25 out. 2016.

FACULDADE de Educação da Universidade de São Paulo. Nota de Repúdio à Medida Provisória 746 - Reforma do Ensino Médio. Disponível em: <http://www4.fe.usp.br/nota-de-repudio-a-medidaprovisoria-746>. Acesso em: 24 out. 2016.

FRANCO, Alexandre de Paula. Ensino Superior no Brasil: cenário, avanços e contradições. Jornal de Políticas Educacionais, São Paulo, v. 1, n. 4, p. 53-63, jun.-dez 2008.

GAJARDONI, Fernando da Fonseca. As transformações do direito e o novo perfil do profissional jurídico. Revista Jurídica da Universidade de Franca, Franca, v. 6, p. 54-68, 2001.

GASPARIN, João Luiz. Uma didática para a pedagogia histórica-crítica. 3 ed. Campinas, SP: Autores Associados, 2005.

GODOY, Arilda Schimidt. Revendo a aula expositiva. In: MOREIRA, Daniel A. (org). Didática do ensino superior: técnicas e tendências. São Paulo: Pioneira, 1977.

LÔBO, P. L. Neto. O novo conteúdo mínimo dos cursos jurídicos. In: OAB ENSINO JURÍDICO: Novas Diretrizes Curriculares, Conselho Federal da OAB, Brasília, 1996.

LYRA FILHO, Roberto. O que é direito. São Paulo: Brasiliense, 1982. Coleção Primeiros Passos.

MONTEIRO, Geraldo Tadeu Moreira. Metodologia da pesquisa jurídica: Manual para a elaboração e apresentação de monografias. Rio de Janeiro, 2001.

MOSSINI, Daniela E. de S. Ensino Jurídico: história, currículo e interdisciplinaridade. 2010. 256 f. Tese (Doutoramento em Educação: Currículo). Pontifícia Universidade Católica de São Paulo -PUC, São Paulo, 2010. Disponível em: <https://sapient 
ia.pucsp.br/bitstream/handle/9534/1/Daniela\%20Emmerich\%20de\%20Souza\%20Mossini.pdf>. Acesso em: 30 out. 2016.

NUSSBAUM, Martha. Sem fins lucrativos: Por que a democracia precisa das humanidades. 1 ed. São Paulo: WMF Martins Fontes, 2015.

POMPEU, Gina Vidal Marcílio; SAMPAIO, Natércia Siqueira. Liberdade e igualdade: condicionamentos democráticos para o desenvolvimento humano, para o crescimento econômico e à estabilidade social. In POMPEU, Gina Vidal Marcílio; CARDUCCI, Michele; SÁNCHEZ, Miguel Revenga. Direito constitucional nas relações econômicas: entre o crescimento econômico e o desenvolvimento humano. Rio de Janeiro: Lumen Juris, 2014.

REALE, Miguel. Lições preliminares de direito. 27 ed. São Paulo: Saraiva, 2007.

VASCONCELOS, Alex Bretas. Educação Democrática Como Pedra Angular da Participação Social e Política: desafios e oportunidades. Administração pública e gestão social, Belo Horizonte, v. 2, n. 6, p. 82-87, abr-jun. 2014. 
